\title{
Northern Hemisphere Extratropical Cyclones: A Comparison of Detection and Tracking Methods and Different Reanalyses
}

\author{
C. C. RAIBLE \\ Climate and Environmental Physics, Physics Institute, University of Bern, Bern, Switzerland \\ P. M. Della-Marta* \\ Institute of Geography, University of Bern, Bern, Switzerland \\ C. SCHWIERZ ${ }^{+}$ \\ Institute for Atmospheric and Climate Science, ETH Zurich, Zurich, Switzerland \\ H. WERNLI \\ Institute for Atmospheric Physics, University of Mainz, Mainz, Germany \\ R. BLENDER \\ Meteorological Institute, University of Hamburg, Hamburg, Germany
}

(Manuscript received 12 January 2007, in final form 28 June 2007)

\begin{abstract}
The applicability of three different cyclone detection and tracking schemes is investigated with reanalysis datasets. First, cyclone climatologies and cyclone characteristics of the 40-yr ECMWF Re-Analysis (ERA40) are compared with the NCEP-NCAR dataset using one method. ERA-40 shows systematically more cyclones, and therefore a higher cyclone center density, than the NCEP-NCAR reanalysis dataset. Geostrophically adjusted geopotential height gradients around cyclone centers, a measure of cyclone intensity, are enhanced in ERA-40 compared with the NCEP-NCAR reanalysis dataset. The variability of the number of cyclones per season is significantly correlated between the two reanalysis datasets, but time series of the extreme cyclone intensity exhibit a higher correlation. This suggests that the cyclone intensity is a more robust measure of variability than the number of cyclones. Second, three cyclone detection and tracking schemes are compared, based on the ERA-40 dataset. In general the schemes show a good correspondence. The approaches differ in technical aspects associated with the cyclone identification and the tracking procedure, leading to deviations in cyclone track length. However, it is often not clear which scheme is correct or incorrect. With the application of lifetime thresholds, some of the cyclone tracks are too short to be included in statistical measures of cyclones. Nevertheless, consequences of these differences in mean cyclone characteristics are minor, but for specific research questions-for example, what is the cyclone activity in the Mediterranean in winter-the users should be aware of these potential differences and adjust their scheme if necessary. A trend analysis of cyclone characteristics shows that results appear to be sensitive to both the choice of cyclone detection and tracking schemes and the reanalysis dataset.
\end{abstract}

\footnotetext{
* Current affiliation: MeteoSwiss, Zurich, Switzerland.

+ Current affiliation: School of Earth and Environment, Institute for Atmospheric Science, University of Leeds, Leeds, United Kingdom.
}

Corresponding author address: C. C. Raible, Climate and Environmental Physics, Physics Institute, University of Bern, Sidlerstrasse 5, CH-3012 Bern, Switzerland.

E-mail: raible@climate.unibe.ch

DOI: $10.1175 / 2007 M W R 2143.1$

(C) 2008 American Meteorological Society 


\section{Introduction}

In the midlatitudes, the variability of weather and climate on a day-to-day basis is related to traveling high- and low-pressure systems. Lows or cyclones are a major source of natural hazards. For example, the series of storms Daria, Vivian, and Wiebke in JanuaryFebruary 1990, which intensified over Scandinavia, led to widespread wind damage in western Europe and related losses in human lives. They caused damages of more than 10 billion U.S. dollars (Goyette et al. 2001). Such intense events have also led to a growing interest in storms and their variability by insurance companies over the last years (Mailier et al. 2006).

Going back to the late nineteenth century, first studies (Köppen 1881; Van Bebber 1891) recognized the key role of cyclones in synoptic-scale variability. They manually characterized cyclones by their tracks (a Lagrangian measure) and their spatial variability (an Eulerian measure).

One Eulerian measure is the so-called dynamic storm track, which is defined as a region of enhanced standard deviation of the bandpass filtered 500-hPa geopotential height (Blackmon 1976; Wallace et al. 1988; Lau 1988). Because of the time filtering of 2.5-6 days, the storm track is restricted to the characteristic time scale of synoptic cyclones; however, a considerable amount of synoptic-scale variability within this frequency band is not related to cyclones but to large-scale waves and highpressure systems.

Besides this Eulerian view, Lagrangian techniques were developed (Murray and Simmonds 1991a; Simmonds et al. 2003; Ueno 1993; König et al. 1993; Hodges 1994; Hodges et al. 2003; Sinclair 1994, 1997; Blender et al. 1997; Gulev et al. 2001; Zolina and Gulev 2002; Wernli and Schwierz 2006). These techniques basically consist of two steps: cyclone detection and cyclone tracking. Some methods define lows as minima in surface pressure or geopotential height (Blender et al. 1997; Gulev et al. 2001; Wernli and Schwierz 2006) whereas other methods use the vorticity fields (e.g., Sinclair 1994). Murray and Simmonds (1991a) used maxima in vorticity or the Laplacian of sea level pressure/geopotential height as starting point and searched for a nearby pressure minimum. König et al. (1993) and Hodges (1994) applied a combination of sea level pressure minima and vorticity maxima. However, not only do the detection techniques differ from scheme to scheme but the tracking methods do also. Ueno (1993), König et al. (1993), Sinclair (1994), and Blender et al. (1997) used a next-neighbor search. A prediction and matching approach has been used by Murray and Sim- monds (1991a) and Wernli and Schwierz (2006). A three-dimensional variational method has been developed by Hodges (1994) and Hodges et al. (2003). These differences in detection and tracking can affect the statistics of cyclone characteristics. For instance, Sinclair (1995) showed that cyclone tracks identified with a pressure minima approach appear at higher latitudes than those estimated by a vorticity-based method.

The techniques have been applied to general circulation model (GCM) output. For example, Murray and Simmonds (1991a) and König et al. (1993) investigated GCM output and compared it with reanalysis data. Raible and Blender (2004) applied the method of Blender et al. (1997) to simulated data and found that cyclone tracks and their corresponding variability are a sensitive measure to detect discrepancies between simulations with different ocean representations. Other studies have presented the role of cyclone-related variability on the generation of decadal variations of circulation patterns (Raible et al. 2004; Luksch et al. 2005). In climate change scenario simulations Schubert et al. (1998) found a northward shift of cyclone tracks in a warmer climate state. Leckebusch and Ulbrich (2004) confirmed this result and additionally investigated the intensity of cyclones. They found that North Atlantic cyclones intensify in projections of future climate compared with a control simulation for present day conditions, whereas no significant cyclone intensity changes were found in other studies (Kharin and Zwiers 2000, 2005). Cyclone characteristics have also been analyzed for a distinct past climate state, the Maunder Minimum, which was a prolonged cold period from 1640 to 1715 (Raible et al. 2007). For this period, cyclone center density shifts southward at the end of the midlatitude cyclone track compared with the recent climate. Cyclone intensity was possibly higher in the Maunder Minimum versus today, which is supported by proxy evidence (Björck and Clemmensen 2004; De Jong et al. 2006). An obvious reason for these differences lies in the use of different GCMs, but it is also possible that the results could be influenced by the applied detection and tracking methods, which differ substantially.

Besides the GCM studies, authors applied their methods to reanalyses to investigate changes within the observational period. For example, Sickmöller et al. (2000) analyzed the trends in cyclones, utilizing the data from the 15-yr European Centre for MediumRange Weather Forecasts (ECMWF) Re-Analysis (ERA-15). Hodges et al. (2003) showed that the frequency and the intensity of cyclones differ between ERA-15 and the National Centers for Environmental Prediction-National Center for Atmospheric Research 
(NCEP-NCAR) reanalysis. This finding is confirmed by Hanson et al. (2004) who focused on comparing North Atlantic cyclones using the two datasets. Recently, Wang et al. (2006) compared cyclone characteristics and trends in ERA-40 and the NCEP-NCAR reanalysis, identifying an increasing trend in cyclone activity over northern Europe and a significant decreasing trend over the midlatitude North Atlantic. They explain this change by a northward shift of the cyclone track, in agreement with a study by Trigo (2006). This trend behavior in the North Atlantic was also found by Gulev et al. (2001), who identified a strong positive trend of cyclone intensity in the Pacific. This is again confirmed by Simmonds and Keay (2002) and Raible (2007); however, both studies did not find any significant trend in the North Atlantic cyclone intensity, which is in contrast to Gulev et al. (2001). Note that Gulev et al. (2001) and Simmonds and Keay (2002) use the NCEP-NCAR reanalysis whereas Raible (2007) applied their scheme to the ERA-40 dataset.

Clearly, cyclone tracks and the frequency and intensity of cyclones depend not only on the dataset but also on the detection and tracking algorithms used. Therefore, the purpose of this study is twofold. First, the NCEP-NCAR reanalysis dataset is compared to ERA40 reanalysis, employing one specific cyclone detection and tracking method. We explore seasonal changes and trends in different cyclone characteristics to complement and provide additional information to a series of previous studies (Hodges et al. 2003; Trigo 2006; Wang et al. 2006). The main goal of this section is to provide an estimate of uncertainty due to different reanalyses for the period 1961-90. The second part of the study determines the uncertainty associated with different cyclone detection and tracking algorithms. Therefore, three methods (Blender et al. 1997; Murray and Simmonds 1991a; Wernli and Schwierz 2006) are applied to the ERA-40 dataset and compared with each other. In particular, cyclone tracks are individually compared with a method of Blender and Schubert (2000). The focus is on cyclones with a lifetime of at least $72 \mathrm{~h}$, which is a particular subcategory of extratropical cyclones, that is, on average rather strong cyclones.

The paper is outlined as follows: After introducing the reanalysis datasets and the cyclone detection and tracking methods in section 2 , we present the comparison of the reanalysis data, using one cyclone detection and tracking method for all seasons (section 3). In section 4 the different methods are compared, using the ERA-40 data for the winter and the summer seasons. Section 5 summarizes and concludes the study.

\section{Data and analysis techniques}

\section{a. Reanalysis data}

Two reanalysis datasets are used in this study. The National Centers for Environmental Prediction and the National Center for Atmospheric Research provide a reanalysis dataset from 1948 to 2005 (Kalnay et al. 1996; Kistler et al. 2001). The reanalysis system includes the operational NCEP-NCAR global spectral model with a horizontal resolution of T62 (triangular truncation of 62 waves corresponding to a regular longitude-latitude grid of approximately $2^{\circ} \times 2^{\circ}$ ) and 28 vertical levels. To assimilate observations, NCEP-NCAR uses the optimum interpolation technique. The second reanalysis is obtained from the European Centre for Median-Range Weather Forecasts, which released its new reanalysis dataset (ERA-40) for the years 1957-2002 (Uppala et al. 2005). The ERA-40 dataset is generated with the medium-range forecasting system of ECMWF in a horizontal resolution of T159 (approximately $1^{\circ} \times 1^{\circ}$ ) and 60 vertical levels. In contrast to NCEP-NCAR, ECMWF uses the three-dimensional variational technique to assimilate observations in their system. For this study, both datasets are interpolated to a regular $2.5^{\circ} \times 2.5^{\circ}$ grid with a time resolution of $6 \mathrm{~h}$ (observation times: 0000, 0600, 1200, and 1800 UTC).

For the comparison between the schemes, we concentrate on a 30-yr period from 1961 to 1990 . This period was chosen because of two reasons: the World Meteorological Organization defines climatological means to be $30-y r$ averages, and this specific period is often used as a time slice for highly resolved climate control simulations in the climate change community (Wild et al. 2003). All schemes detailed below are applied to geopotential height data at the constant pressure surface of $1000 \mathrm{hPa}$, denoted as z1000.

\section{b. Cyclone detection and Lagrangian tracking methods}

In the following we present a synopsis of three different schemes including their principle assumptions. More details of the methods, which are based on substantially different concepts, can be found in the corresponding literature.

\section{1) University of HAMBURg APPROACH}

In the University of Hamburg tracking scheme (HAM; Blender et al. 1997), lows are identified as minima of the z1000 field within a neighborhood of 8 grid points. To neglect very weak minima, a mean gradient of at least $20 \mathrm{gpm}(1000 \mathrm{~km})^{-1}$ in a radius of 1000 $\mathrm{km}$ is required. The gradient is also used as a cyclone 
intensity measure. It is superior to the central pressure of a cyclone as a measure of cyclone intensity, because the central pressure changes with the regional (latitudinal) climate mean. Moreover, mountain regions with an altitude higher than $1000 \mathrm{~m}$ are excluded because of extrapolation uncertainties of the z1000 field in the reanalysis datasets. The identified minima are connected to cyclone trajectories by a next-neighbor search in the preceding z1000 field within a distance of $1000 \mathrm{~km}$ in 24 h. Furthermore, the method requires that a minimum gradient of $30 \mathrm{gpm}(1000 \mathrm{~km})^{-1}$ is exceeded at least once during the life cycle of the considered cyclone. Note that the thresholds for the z1000 gradient are low enough to detect cyclones in the initial stage and during weaker decay phases of their life cycle.

\section{2) ETH APPROACH}

The procedure of the Swiss Federal Institute of Technology [Eidgenössische Technische Hochschule (ETH)] Zurich, (Wernli and Schwierz 2006) is twofold and consists of an identification scheme that yields cyclone frequency fields and a separate tracking algorithm. The detection procedure is undertaken in two steps. (i) As with the HAM approach, cyclone centers are determined as local minima in the z1000 field. (ii) The outermost closed contour of the base field (here z1000) is determined for each cyclone center; that is, no other minimum can be located within this contour. The enclosed area is considered as the cyclone field. A sensitive parameter for this methodology is the interval at which the search for the outermost closed contour is undertaken. In this study, it is set to $15 \mathrm{gpm}$. Cyclone centers, encircled by at least one closed contour, are used for the tracking scheme. This means that weaker minima are excluded from the tracking part of the method. The tracking differs from the HAM approach in that for every cyclone center at time $t_{n}$ a first guess is calculated for its position at the next time step $t_{n+1}$. A cyclone center located at $\mathbf{x}_{P}$ at the time $t_{n+1}$ is regarded as a possible candidate to continue the cyclone track $\mathbf{x}_{Q}\left(t_{1}\right), \ldots, \mathbf{x}_{Q}\left(t_{n}\right)$ if the distance between $\mathbf{x}_{P}\left(t_{n+1}\right)$ and the first guess location of $\mathbf{x}_{Q}$ at time $t_{n+1}, \mathbf{x}_{Q}^{*}\left(t_{n+1}\right)$, is less than a certain threshold distance $D=1000 \mathrm{~km}$. Then the cyclone center at $t_{n+1}$ is taken as the next track position. If there is more than one candidate the one closest to the first guess position is chosen. The ETH method has the advantage that it determines cyclone frequency fields from the base field (here z1000) directly without invoking all the difficulties inherent in tracking procedures. Such cyclone frequency fields are, however, not considered in this study. A more detailed discussion and the climatological distributions of cyclones, based on sea level pressure data, are presented in Wernli and Schwierz (2006). They also discuss the sensitivity of the identification of the outermost closed contour to different search intervals. For the intercomparison study presented here, only the tracked cyclone centers have been used. Note that they are subject to the subjectively chosen tracking parameter $D$ and the first guess calculation.

\section{3) Australian ApProAch}

The Australian (AUS) scheme (Murray and Simmonds 1991a) first models the z1000 field with a bicubic spline to help locate minima between grid points. However on output from the scheme, cyclones are assigned to the nearest grid point of the original grid, to be comparable with the other schemes. To identify shallow minima in the presence of deeper ones, each grid point in the array is scanned to find the maximum in the z1000 Laplacian, $\nabla^{2} \mathrm{z} 1000$, from the four surrounding points. These maxima are then used as a starting point for an iterative procedure that locates the pressure minimum. The interpolated (bicubic spline) first and second derivatives of the field are used to define an ellipsoid whose center is the next point in the search to find the local minima. The minima detection usually converges to the field minima within three to four iterations. One of the advantages of this approach to finding cyclone centers is that it can find centers that are between grid points and also find centers that do not have closed contours. Murray and Simmonds (1991a) refer to these minima as "open depressions." They usually occur along trough axes near points of inflexion on the z1000 field. Since neither of the other minima detection methods can find comparable systems this feature of the AUS method was not used here. A key parameter in the minima detection part of this scheme is the concavity criterion, which specifies the minimum average Laplacian of a system at a radius of $3^{\circ}$ latitude (at the equator $1^{\circ}$ latitude $\approx 116 \mathrm{~km}$ ) to be equal to $2.22 \mathrm{gpm}\left({ }^{\circ} \text { latitude }\right)^{-2}$. The tracking of lows uses a method of assigning probabilities to each plausible minimum center at the next time step based on a comparison with the extrapolated trajectory of the current cyclone. The extrapolation method uses a weighted combination of the cyclone's current trajectory and the climatologically preferred movement of the cyclone as well as an estimate of the cyclone's central geopotential height, based on the cyclone's previous geopotential height tendency. Since the time resolution of the data is high these weighting factors were set close to unity, implying that both the persistence in movement and central tendency is high. The cyclone tracking procedure is repeated three times for each time step to help identify the most likely track. In the 
first iteration the zonally averaged zonal and meridional cyclone velocity components (based on cyclones tracked using NCEP-NCAR $2.5^{\circ} \times 2.5^{\circ}$, 6-hourly reanalyses) are used in the extrapolated trajectory calculation. On subsequent iterations of the tracking procedure, the zonal and meridional cyclone velocities at each grid point based on the previous track calculations are used. In this way the tracking procedure converges to a stable solution of the cyclone tracks. The AUS method has many user parameters in its cyclone location and tracking procedure. The details of the most important parameters are described in Murray and Simmonds (1991a,b) and Simmonds et al. (1999). The parameters are set according to the advice contained within these papers and the author's visualization techniques and comparison with manual analyses.

\section{c. Comparison methods}

The comparison of different reanalyses and cyclone detection and tracking schemes focuses on cyclones having a minimum lifetime of $72 \mathrm{~h}$. This threshold generally ensures that, on average, rather strong cyclones are selected. Moreover, cyclone tracks which pass areas of orography higher than $1000 \mathrm{~m}$ are excluded. Two comparison methods are used. The first compares the mean behavior by calculating the cyclone center density, which is the number of cyclones normalized by the total observation time and an area of $1000^{2} \mathrm{~km}^{2}$. For example, a value of $10(1000 \mathrm{~km})^{-2}$ at one grid point is equivalent to saying that cyclone centers occupy an area of $1000^{2} \mathrm{~km}^{2}$ around that grid point for $10 \%$ of the total observation times. Note that this calculation was performed on each scheme in the same manner; other measures of cyclone system density defined in Murray and Simmonds (1991a), Blender et al. (1997), and Wernli and Schwierz (2006) were not used to ensure consistency in this statistic. The second method, designed to show the interannual variability of cyclone characteristics, simply counts the seasonal total number of cyclones.

To compare individual cyclone tracks we use the method of Blender and Schubert (2000), a method that analyzes the common cyclone tracks in two different datasets to obtain a quantitative measure of the agreement. The method works as follows: First, each cyclone track in the dataset denoted $\mathrm{A}$ is compared with each cyclone track in dataset $\mathrm{B}$ to find the nearest cyclone track. Here a spatiotemporal distance is used, which includes differences in locations and differences in the observation times of cyclones (see appendix). Hence, the observation times (including their total lifetime) as well as the spatial positions may be different. After this identification, the same analysis is performed for the set
$\mathrm{B}$ to find the nearest cyclone tracks in A for each track in B. Finally, the two nearest-neighbor tables are compared to extract those pairs of tracks in A and B that are nearest neighbors of each other (in terms of space and time; see appendix for more explanation). These best-matched cyclone tracks are assumed to be the same real cyclone. The number of these matched tracks is the measure of the agreement of both sets. The absolute spatiotemporal distance of such pairs of tracks is not relevant since previous analyses show that one-toone pairs identified in this way have small distances, otherwise the nearest-neighbor relationship would have been found by chance. Note that the method uses individual cyclone tracks and is thus more detailed than a comparison of cyclone statistics derived from Eulerian fields, such as cyclone densities. An important property of the method is that it is not restricted to equal spatial grids and time steps. However, this is not an issue since in this study all schemes define their track on the same data. Furthermore, it uses no threshold parameters, such as a maximum distance between tracks. In addition to the summary statistics, we also present a case study, which illustrates the differences between tracking algorithms.

\section{Comparison of the reanalysis data}

Extratropical cyclone characteristics of the ERA-40 and the NCEP-NCAR reanalysis datasets are compared over the Northern Hemisphere north of $20^{\circ} \mathrm{N}$ using the HAM cyclone detection and tracking scheme. We focus our results on the midlatitude band $30^{\circ}-75^{\circ} \mathrm{N}$ and two specific regions in the Atlantic (high-latitude North Atlantic $55^{\circ}-70^{\circ} \mathrm{N} ; 45^{\circ} \mathrm{W}-15^{\circ} \mathrm{E}$ and the midlatitude North Atlantic $45^{\circ}-55^{\circ} \mathrm{N} ; 75^{\circ}-10^{\circ} \mathrm{W}$ ) similar to Wang et al. (2006).

The cyclone variability is characterized by the time series of the number of cyclones, reaching a lifetime of at least $72 \mathrm{~h}$ (Fig. 1). The number of cyclones is analyzed separately for each ocean basin-the Atlantic $\left(30^{\circ}-75^{\circ} \mathrm{N}, 100^{\circ} \mathrm{W}-60^{\circ} \mathrm{E}\right)$ and the Pacific $\left(30^{\circ}-75^{\circ} \mathrm{N}\right.$, $\left.90^{\circ} \mathrm{E}-110^{\circ} \mathrm{W}\right)$. For both basins and for all seasons, a greater number of cyclones are found in ERA-40 than in the NCEP-NCAR reanalysis. The strongest difference appears in summer, resembling findings of Wang et al. (2006) and Trigo (2006). These differences can be explained by the different horizontal resolution of the models, which are used to generate the reanalysis datasets. Note that the NCEP-NCAR model uses T62, whereas the ECMWF system is integrated with T159. Even if the high-resolution data is interpolated to the same grid (here a regular $2.5^{\circ} \times 2.5^{\circ}$ grid) the simulated lows could achieve deeper values than at lower resolu- 
(a)

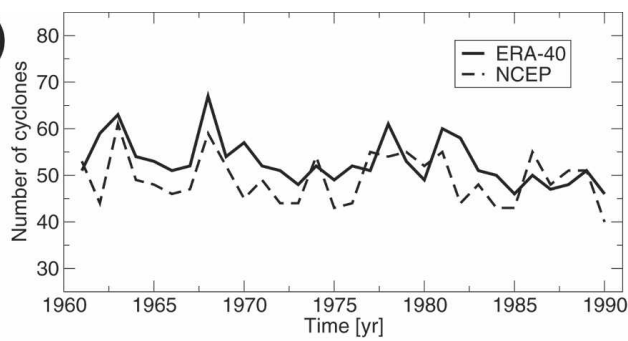

(c)

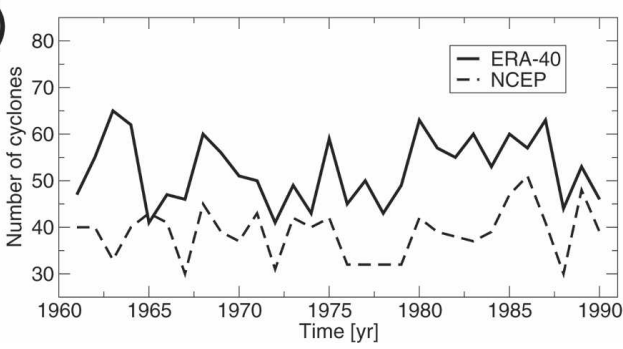

(b)

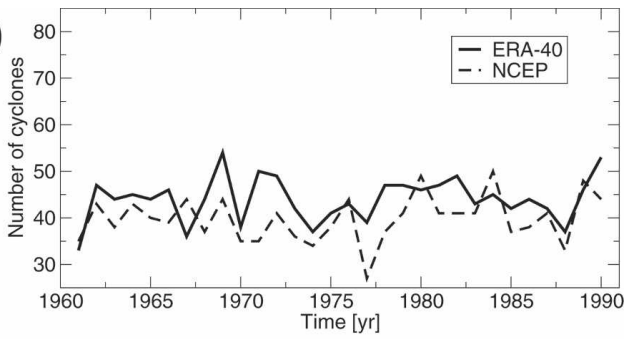

(d)

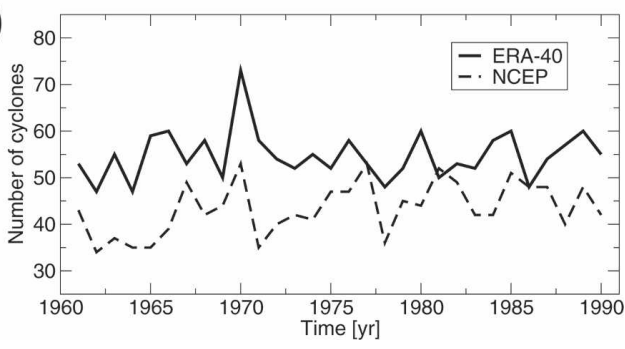

FIG. 1. Number of cyclones with a lifetime of at least $72 \mathrm{~h}$ in (a), (b) DJF and (c), (d) JJA for the (a), (c) Atlantic $\left(30^{\circ}-75^{\circ} \mathrm{N}, 100^{\circ} \mathrm{W}-60^{\circ} \mathrm{E}\right)$ and the (b), (d) Pacific $\left(30^{\circ}-75^{\circ} \mathrm{N}, 90^{\circ} \mathrm{E}-110^{\circ} \mathrm{W}\right)$ using the HAM approach. Solid lines are the ERA-40; dashed lines are the NCEP-NCAR reanalysis.

tion. Therefore, the z1000 gradients are stronger in simulations with a high horizontal resolution (Blender and Schubert 2000). In some years, however, more cyclones are found in the NCEP-NCAR reanalysis, suggesting that the number of cyclones might be a sensitive and unstable measure for cyclone variability. Still, the number of cyclones in each dataset shows correlation coefficients between 0.61 and 0.8 , which are statistically significant (5\% level) in all seasons and in both basins.

The mean cyclone center density as defined above for cyclone tracks lasting at least $72 \mathrm{~h}$ is illustrated in terms of ERA-40 data as well as the difference between the NCEP-NCAR reanalysis and ERA-40 (Fig. 2). Clearly, the strongest discrepancies occur near high orography in all seasons, in particular around Greenland. These differences are caused by differences in the reanalysis model orography and confirm findings of Hodges et al. (2003), who used a shorter analysis period. The difference in Hudson Bay is mainly caused by differences in the land-sea mask, whereas the deviations at the southern tip of Greenland and nearby Iceland are probably caused by lee effects of the Greenland massif. In general, we see that cyclone center density is higher in ERA-40 than in the NCEP-NCAR reanalysis. In summer more cyclones are found over the Gulf of California in ERA-40. Again this can be traced back to resolution and land-sea mask issues. Another difference is the underestimation of heat lows in northern Africa by the NCEP-NCAR reanalysis.

Note that the interpolation technique used for the ERA-40 data has little influence on the results. To test this, results of the standard interpolation technique are compared with results obtained from ERA-40 data, which are first spectrally truncated to T62 and then interpolated to the regular $2.5^{\circ} \times 2.5^{\circ}$ grid. Differences in cyclone center density between both interpolation techniques are small (not shown).

One way to analyze the seasonality of cyclone tracks is the difference in total cyclone center density between one season and a reference season (Fig. 3, only shown for ERA-40). In this study the winter season (December-February) is chosen as the reference. The strongest seasonal difference is found between winter and summer (Fig. 3b). The pattern in the Pacific shows an eastwest dipole with increased cyclone center density south of the Aleutian Islands and a decrease near Japan in winter (compared with summer). There are positive differences in the lee of Kamchatka and the Alaskan Sea, which are two important cyclone genesis regions in winter in the Pacific. In the Atlantic region, a southward shift of cyclone center density is mainly found over Europe, leading to a distinct increase of cyclones in the Mediterranean in winter. The transition seasons show similar but weaker patterns in both regions (Figs. 3a,c). Note that, although there is a difference between the total cyclone center density between the reanalyses (Fig. 2), the seasonality patterns have similar amplitudes and structures for both reanalysis datasets.

Another important characteristic of cyclones is their intensity. There are various definitions of cyclone intensity (Simmonds and Keay 2000; Leckebusch and Ulbrich 2004; Trigo 2006); we use the geopotential height gradient of cyclones in a radius of $1000 \mathrm{~km}$ which is geostrophically adjusted to $60^{\circ} \mathrm{N}$ (Raible 2007). The 

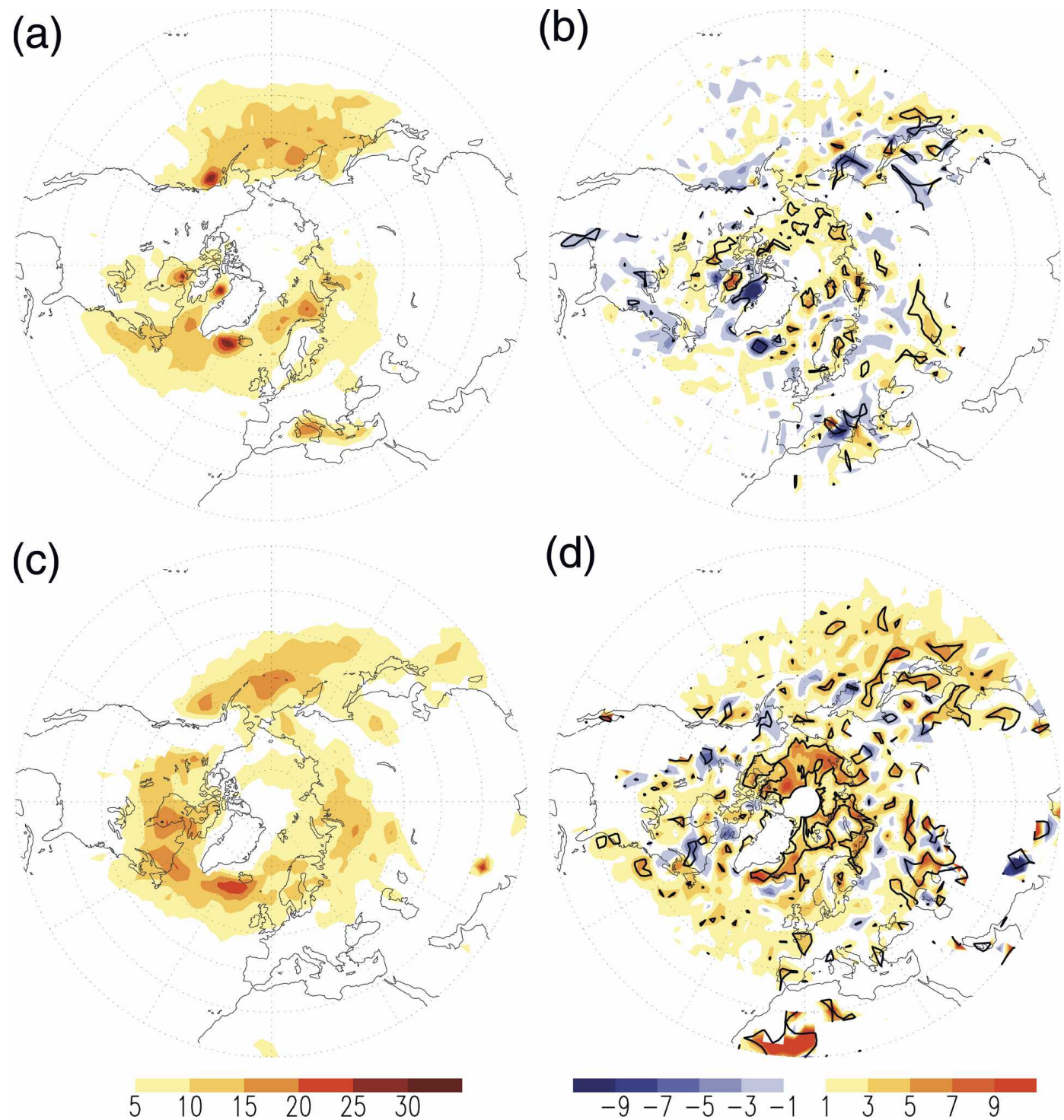

FIG. 2. Total cyclone center density \{which exceed a lifetime of at least $72 \mathrm{~h}\left[\mathrm{No} .(1000 \mathrm{~km})^{-2}\right]$ for the period 1961-90, using the HAM approach: (a), (b) DJF and (c), (d) JJA. (a), (c) The mean cyclone center density of ERA-40, and (b), (d) the difference between ERA-40 and the NCEP-NCAR reanalysis. Thick contours indicate the $5 \%$ significance level.

geostrophically adjusted geopotential height $z_{\text {geostr }}($ lon, lat) is obtained as follows:

$$
z_{\text {geostr }}(\text { lon, lat })=z(\text { lon, lat }) \frac{\sin \left(\pi \text { lat }_{\text {ref }} / 180\right)}{\sin (\pi \text { lat } / 180)},
$$

with $z$ (lon, lat) the geopotential height, lon and lat the longitude and latitude, and lat ${ }_{\text {ref }}=60^{\circ} \mathrm{N}$ the reference latitude. Thus, this intensity measure represents the geostrophic wind rather than the pure geopotential height gradient. The mean frequency distribution of the strength of the cyclones (reaching a lifetime of at least $72 \mathrm{~h}$ ) in a season is estimated from these gradients.
Again, the analysis is applied separately to the ocean basins and seasons (Fig. 4). Both datasets exhibit a positively skewed distribution, but geopotential height gradients are stronger in the ERA-40 than in NCEPNCAR reanalyses. This resembles findings by Wang et al. (2006) who used a different intensity measure in slightly smaller regions of both basins. This heavy tail in ERA-40 can be traced back to the different horizontal resolution and the different assimilation techniques of the two datasets, as, for example, optimal interpolation tends to smooth the geopotential height fields leading to less pronounced minima. The cyclone intensity also 

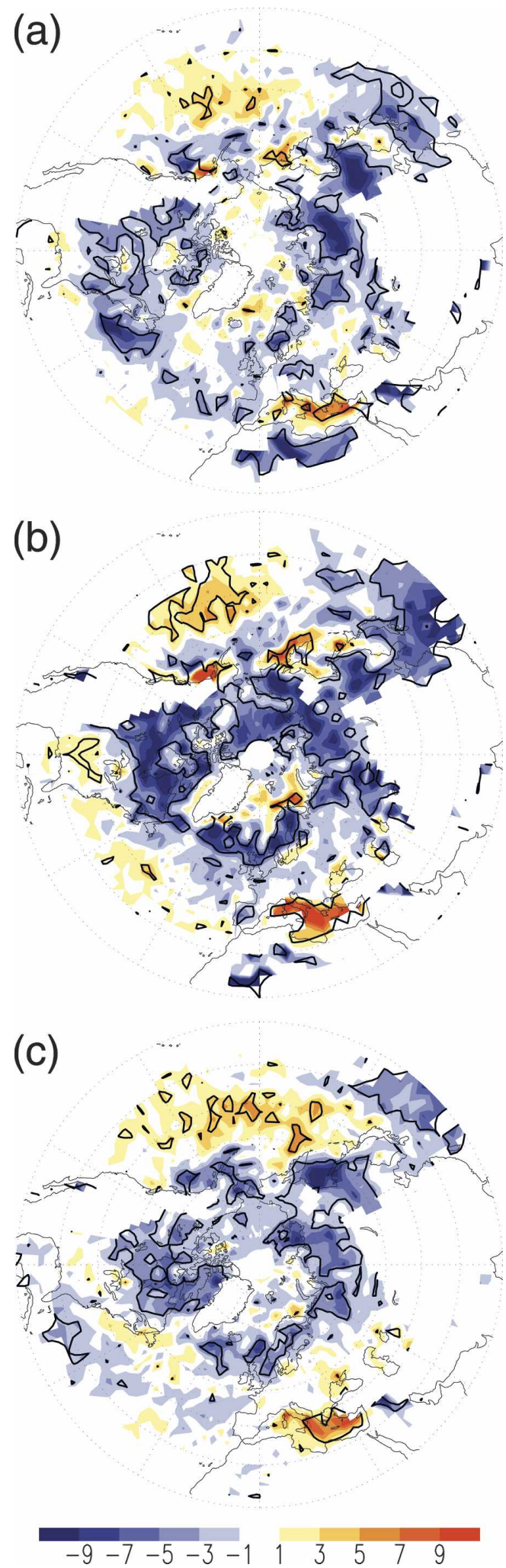

FIG. 3. Difference in total density of cyclone centers \{which exceed a lifetime of at least $72 \mathrm{~h}\left[\right.$ No. $\left.\left.(1000 \mathrm{~km})^{-2}\right]\right\}$ between the winter (DJF) and all other seasons for ERA-40 and the period 1961-90, using the HAM approach: (a) DJF - MAM, (b) DJF JJA, and (c) DJF - September-November (SON). Thick contours indicate the $5 \%$ significance level. shows a seasonal behavior. Clearly, the summer cyclones (Figs. 4c,d) are weaker than the winter cyclones (Figs. 4a,b). Comparing the basins we find that, on average, the cyclone intensity is higher in the Pacific than in the Atlantic. Note that the absolute values of the extreme cyclone intensity depend to a very large degree on the model resolution, which is used to generate the reanalysis dataset. To illustrate the temporal behavior of the extreme cyclone intensity, the 90th percentile of the distribution is calculated separately in each season of a year and for both datasets (not shown). The interannual and decadal variations of the extreme cyclone intensity agree in both datasets, as shown by high correlation coefficients between the ERA-40 and the NCEP-NCAR data. The correlation coefficients vary between 0.89 and 0.94 for both basins and all seasons with no particular seasonality.

The signs of the linear ordinary least squares trends in extreme cyclone intensity (90th percentile), as well as in the number of cyclones and the cyclone activity, which is the product of extreme intensity and number (Raible and Blender 2004; Wang et al. 2006), are presented in Table 1 for the entire period 1957-2002. In some seasons we see significant $(10 \%$ and $5 \%$ level $)$ positive trends of the number of cyclones in both datasets. The deviations between the two reanalyses datasets are remarkable; for example, in spring we identify a significant positive trend for the Atlantic in the NCEP-NCAR reanalysis that is not significant in ERA-40. For the cyclone intensity, significant positive trends are found in all seasons for the Pacific in both datasets resembling findings of Simmonds and Keay (2000). However, significant negative trends of cyclone intensity are found in summer for ERA-40 and in spring for the NCEP-NCAR reanalysis in the Atlantic, in contrast to results presented by Gulev et al. (2001). Differences in trend significance as well as the sign of the trends have consequences for the trends in cyclone activity. For example, there are positive trends in cyclone activity, which primarily relies on a trend in the number of cyclones in the high-latitude North Atlantic during March-May (MAM; NCEP-NCAR). Other examples show a neutral trend in cyclone activity, which seems to be the result of a significant positive trend in number of cyclones cancelling a negative trend in intensity, for example, Atlantic in June-August (JJA; ERA-40 and NCEP-NCAR), or vice versa for the Pacific in December-February (DJF; ERA-40 and NCEP-NCAR). Comparing these trends with Wang et al. (2006), we find a reasonable agreement with the cyclone activity and the number of cyclones in the $\mathrm{Pa}$ cific and the two subregions in the North Atlantic. Moreover, trends of opposite signs are observed be- 
(a)

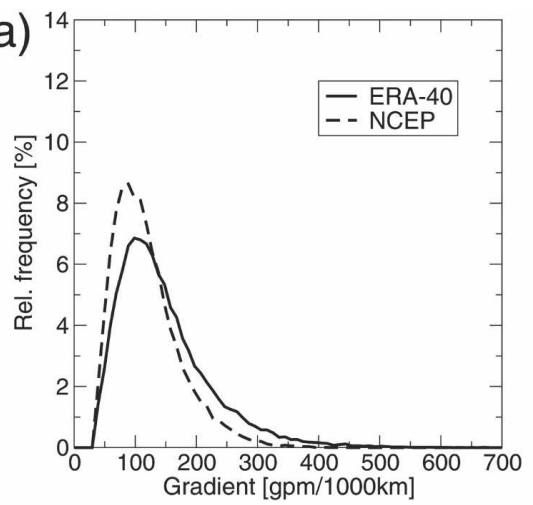

(c)

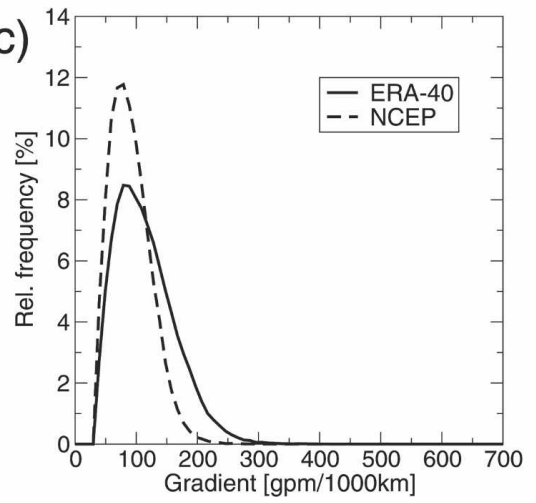

(b)

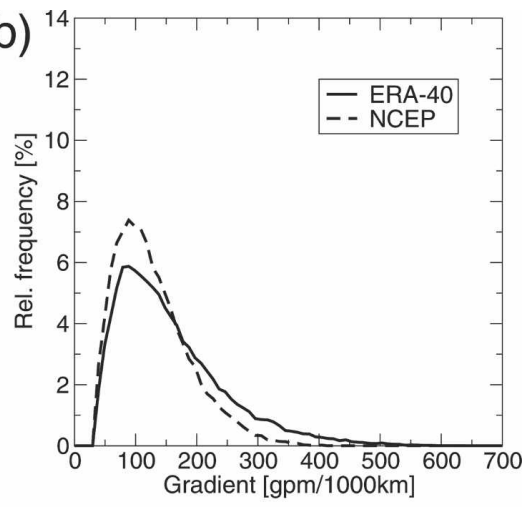

(d)

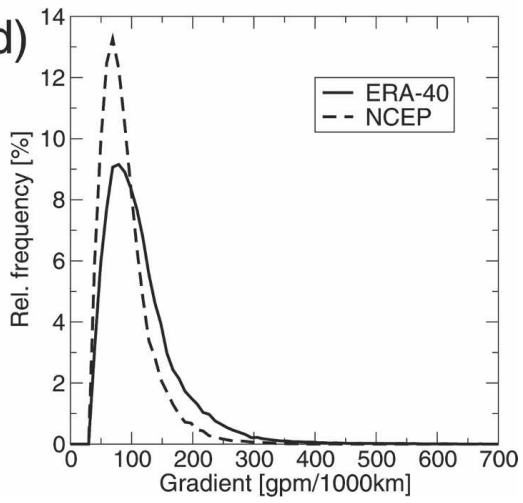

FIG. 4. Seasonal mean distribution of the geopotential height gradient of cyclones with a minimum lifetime of $72 \mathrm{~h}$ in (a), (b) DJF and (c), (d) JJA for the (a), (c) Atlantic $\left(30^{\circ}-75^{\circ} \mathrm{N}\right.$, $\left.100^{\circ} \mathrm{W}-60^{\circ} \mathrm{E}\right)$ and the (b), (d) Pacific $\left(30^{\circ}-75^{\circ} \mathrm{N}, 90^{\circ} \mathrm{E}-110^{\circ} \mathrm{W}\right)$ for the period $1961-90$, using the HAM approach. Solid lines are the ERA-40; dashed lines are the NCEP-NCAR reanalysis; the bin width is $10 \mathrm{hPa}(1000 \mathrm{~km})^{-1}$.

tween the high and midlatitudes of the North Atlantic in nearly all measures and seasons, which also agree with the findings of Wang et al. (2006). Small discrepancies between our findings and Wang et al. (2006) are only found for insignificant trends in a few seasons, for example, for the Pacific in winter. But note that a oneto-one correspondence could not be expected as Wang et al. (2006) use a slightly different region (for the Pacific), a different intensity measure, a different definition of the seasons, and a different detection and tracking tool.

The comparison of individual cyclone tracks of the ERA-40 and the NCEP-NCAR datasets, following the method of Blender and Schubert (2000), is performed separately for all seasons. Table 2 presents the total numbers of cyclones in ERA-40 and the NCEP-NCAR reanalysis, together with the numbers of matching cyclone tracks. The results reveal that the two reanalyses differ considerably. As mentioned previously, it is clear that the higher resolution of ERA-40 simulates more cyclones. However, a higher proportion of cyclone tracks have been matched with the lower-resolution
NCEP-NCAR dataset. The number of cyclones in the NCEP-NCAR reanalysis is lower than those in ERA40 (about $10 \%-20 \%$ ). Therefore, a ratio is obtained as the number of corresponding cyclone tracks divided by the number of NCEP-NCAR cyclones. The correspondence of the tracks varies between $68 \%$ in winter to $77 \%$ in summer. Note that the threshold parameters for detecting the pressure minima and extracting cyclones tracks are identical throughout the year.

\section{Comparison of the cyclone detection and tracking methods}

In the following section we investigate the sensitivity of three different cyclone detection and tracking schemes, using the ERA-40 dataset. As the strongest differences are observed between winter and summer cyclone center density, we concentrate on these seasons. First, similarities and differences of the schemes are discussed by means of a case study. In a second step the focus is on investigating consequences of the individual differences between the schemes in consistency 
TABLE 1. Signs of the trends in the number of cyclones, the extreme cyclone intensity, and the cyclone activity defined as the product of number and extreme intensity for the period $1958-2001$ and different regions: Atlantic $\left(30^{\circ}-75^{\circ} \mathrm{N}, 100^{\circ} \mathrm{W}-60^{\circ} \mathrm{E}\right)$, Pacific $\left(30^{\circ}-75^{\circ} \mathrm{N}\right.$, $90^{\circ} \mathrm{E}-110^{\circ} \mathrm{W}$ ), high-latitude Atlantic (HL-Atl; $55^{\circ}-70^{\circ} \mathrm{N}, 45^{\circ} \mathrm{W}-15^{\circ} \mathrm{E}$ ), and midlatitude Atlantic (ML-Atl; $\left.45^{\circ}-55^{\circ} \mathrm{N}, 75^{\circ}-10^{\circ} \mathrm{W}\right)$. Note that significant trends at the $10 \%$ level are denoted in boldface. At the $5 \%$ level the signs are encircled.

\begin{tabular}{|c|c|c|c|c|c|}
\hline Reanalysis & Region & Season & Number & Intensity & Activity \\
\hline \multirow[t]{16}{*}{ ERA-40 } & \multirow[t]{4}{*}{ Atlantic } & DJF & - & - & - \\
\hline & & MAM & + & - & - \\
\hline & & JJA & $\oplus$ & $\ominus$ & + \\
\hline & & SON & + & + & + \\
\hline & \multirow[t]{4}{*}{ Pacific } & DJF & - & + & + \\
\hline & & MAM & + & + & $\oplus$ \\
\hline & & JJA & + & $\oplus$ & $\oplus$ \\
\hline & & SON & + & + & $\oplus$ \\
\hline & \multirow[t]{4}{*}{ HL-Atl } & DJF & + & + & + \\
\hline & & MAM & - & - & - \\
\hline & & JJA & - & - & - \\
\hline & & SON & - & + & - \\
\hline & \multirow[t]{4}{*}{ ML-Atl } & DJF & - & - & - \\
\hline & & MAM & + & - & + \\
\hline & & JJA & $\oplus$ & + & $\oplus$ \\
\hline & & SON & + & + & + \\
\hline \multirow[t]{16}{*}{ NCEP-NCAR } & \multirow[t]{4}{*}{ Atlantic } & DJF & - & + & + \\
\hline & & MAM & $\oplus$ & $\ominus$ & + \\
\hline & & JJA & $\oplus$ & - & + \\
\hline & & SON & + & + & $\oplus$ \\
\hline & \multirow[t]{4}{*}{ Pacific } & DJF & - & $\oplus$ & + \\
\hline & & MAM & + & $\oplus$ & $\oplus$ \\
\hline & & JJA & $\oplus$ & + & $\oplus$ \\
\hline & & SON & $\oplus$ & + & $\oplus$ \\
\hline & \multirow[t]{4}{*}{ HL-Atl } & DJF & + & $\oplus$ & $\oplus$ \\
\hline & & MAM & + & + & $\oplus$ \\
\hline & & JJA & - & - & - \\
\hline & & SON & - & + & - \\
\hline & \multirow[t]{4}{*}{ ML-Atl } & DJF & - & + & - \\
\hline & & MAM & - & - & - \\
\hline & & JJA & $\oplus$ & + & $\oplus$ \\
\hline & & SON & + & $\oplus$ & + \\
\hline
\end{tabular}

measures and in the mean cyclone characteristics, for example, the total number of cyclones and distributions of track occurrences.

For the case study, all cyclone tracks that contain 1800 UTC 24 December 1980 in their trajectory are chosen. Figure 5 shows the trajectories estimated by the different methods, in which the trajectories identified with the HAM (ETH) method are intentionally displaced northward (southward) by $1^{\circ}$, so that overlapping trajectories are visible. Cyclones with a lifetime shorter than $72 \mathrm{~h}$ are included if at least one scheme identifies the same cyclone with a lifetime greater than $72 \mathrm{~h}$ (dashed lines). The AUS and HAM schemes identify more cyclone tracks (lasting at least $72 \mathrm{~h}$ ) for the selected period than the ETH scheme. To compare these trajectories, the z1000 fields are shown for the period 21-26 December 1988 every $24 \mathrm{~h}$ at 1800 UTC (Fig. 6). The trajectories identified with the AUS and HAM scheme correspond to each other well, but in some cases either scheme finds a longer trajectory than the other one. The cyclone traveling south of Iceland and the one in the central Pacific are identified in all methods. However, the ETH scheme finds fewer and shorter tracks, which is illustrated by the two cyclone tracks with a lifetime shorter than $72 \mathrm{~h}$ (in eastern Canada and in the eastern Pacific). This is mainly due to the restrictive criterion (ETH scheme) for the iden-

TABLE 2. Seasonal numbers of cyclones north to $20^{\circ} \mathrm{N}$ in ERA40, the NCEP-NCAR reanalysis, the corresponding pairs, and the ratio N-pairs/N-NCEP-NCAR for cyclones with a minimum lifetime of $72 \mathrm{~h}$ using the HAM approach for the period 1961-90.

\begin{tabular}{lcccc}
\hline \hline & ERA-40 & NCEP-NCAR & Pairs & Ratio \\
\hline DJF & 3035 & 2760 & 1873 & $68 \%$ \\
MAM & 3642 & 3257 & 2444 & $75 \%$ \\
JJA & 3554 & 2747 & 2101 & $77 \%$ \\
SON & 3428 & 3068 & 2295 & $75 \%$ \\
\hline
\end{tabular}




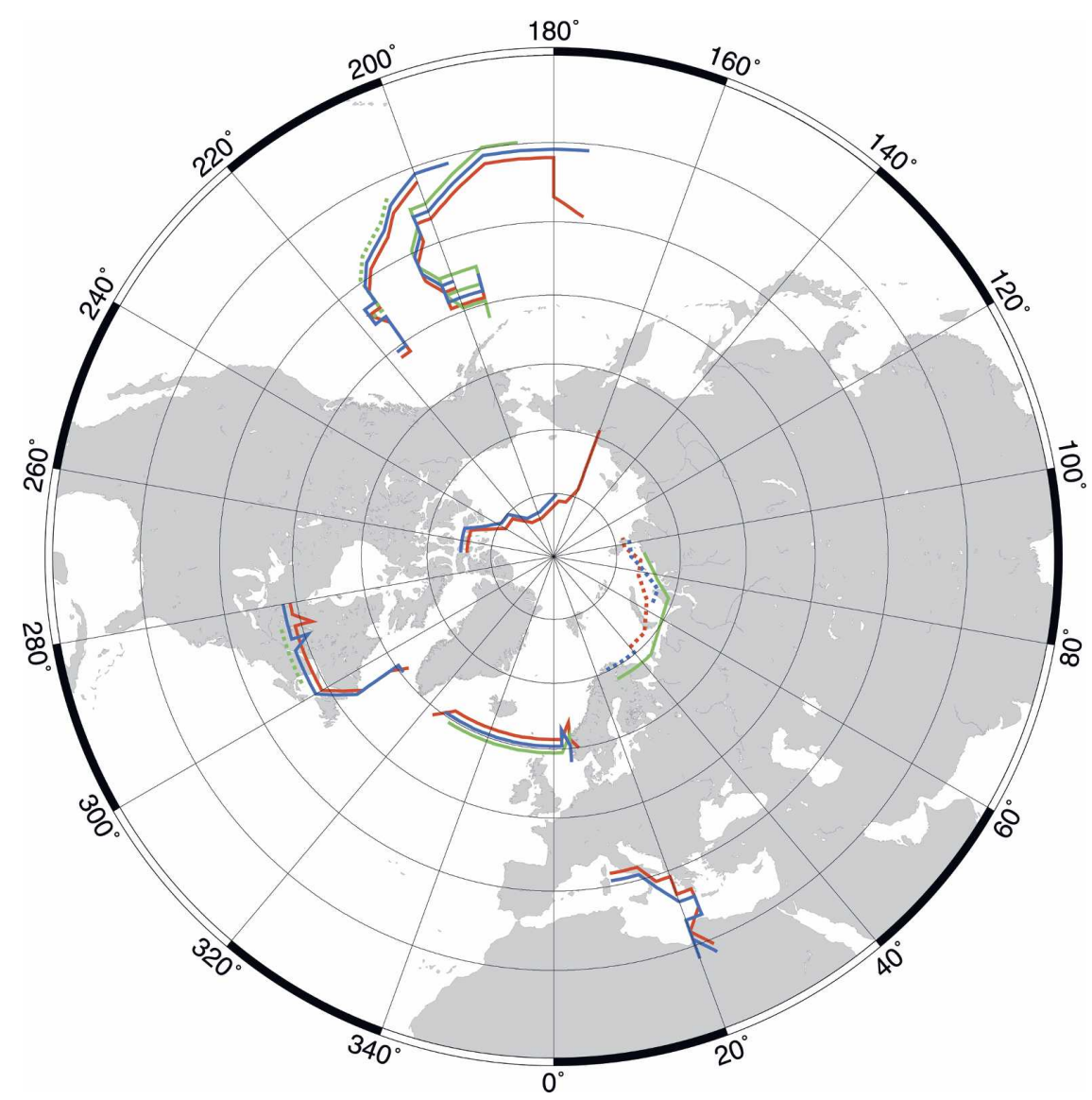

FIG. 5. Case study for all cyclone tracks that include 1800 UTC 24 Dec 1980 in their trajectory: HAM (red; $1^{\circ}$ displaced to the north), AUS (blue), and ETH (green; $1^{\circ}$ displaced to the south). Dotted lines denote cyclones with a lifetime shorter than $72 \mathrm{~h}$, solid lines with a lifetime greater than $72 \mathrm{~h}$.

tification of z1000 minima. There is also the case of the cyclone traveling along the Siberian coast which is only found with the ETH scheme. The AUS scheme splits this cyclone track into two tracks with a lifetime shorter than $72 \mathrm{~h}$, and the HAM scheme identifies this cyclone as a short-living low-pressure system. In the Mediterranean, the cyclone found by HAM and AUS is not found by the ETH method because of the interval parameter in ETH, at which the search for the outermost closed contour is undertaken.

A statistical comparison is summarized in Table 3, based on the application of the individual track comparison technique (section 2c). The AUS and HAM methods show the best agreement. Up to $80 \%(78 \%)$ of the summer (winter) cyclone tracks of the AUS method are also identified with HAM. The agreement with ETH is weaker with only $68 \%$ comparing the ETH with the AUS method. This could be interpreted as a further hint that both methods (AUS and HAM) include a considerable amount of heat lows, weak lows, and pos- sibly also some artificial lows. Nevertheless the agreement between the different methods is in the range of the agreement between the two reanalysis datasets, using the HAM scheme.

One obvious discrepancy between the methods is found in the total number of cyclones. The HAM scheme identifies slightly more cyclones than the AUS scheme, but significantly more than the ETH method in both seasons (Table 4). A reason for these differences is that the parameter setting in the ETH scheme is more rigorous (closed contour condition), which can lead to shorter trajectories as illustrated by the case study (Fig. 5). On the contrary, the AUS and HAM schemes might include a considerable number of very weak lows.

The variability of cyclones does not seem to be affected by the methods. Figure 7 shows the interannual variability of the number of cyclones for the Atlantic and the Pacific in winter and summer separately. We found that the correlation between the time series obtained by the different schemes shows significant coef- 

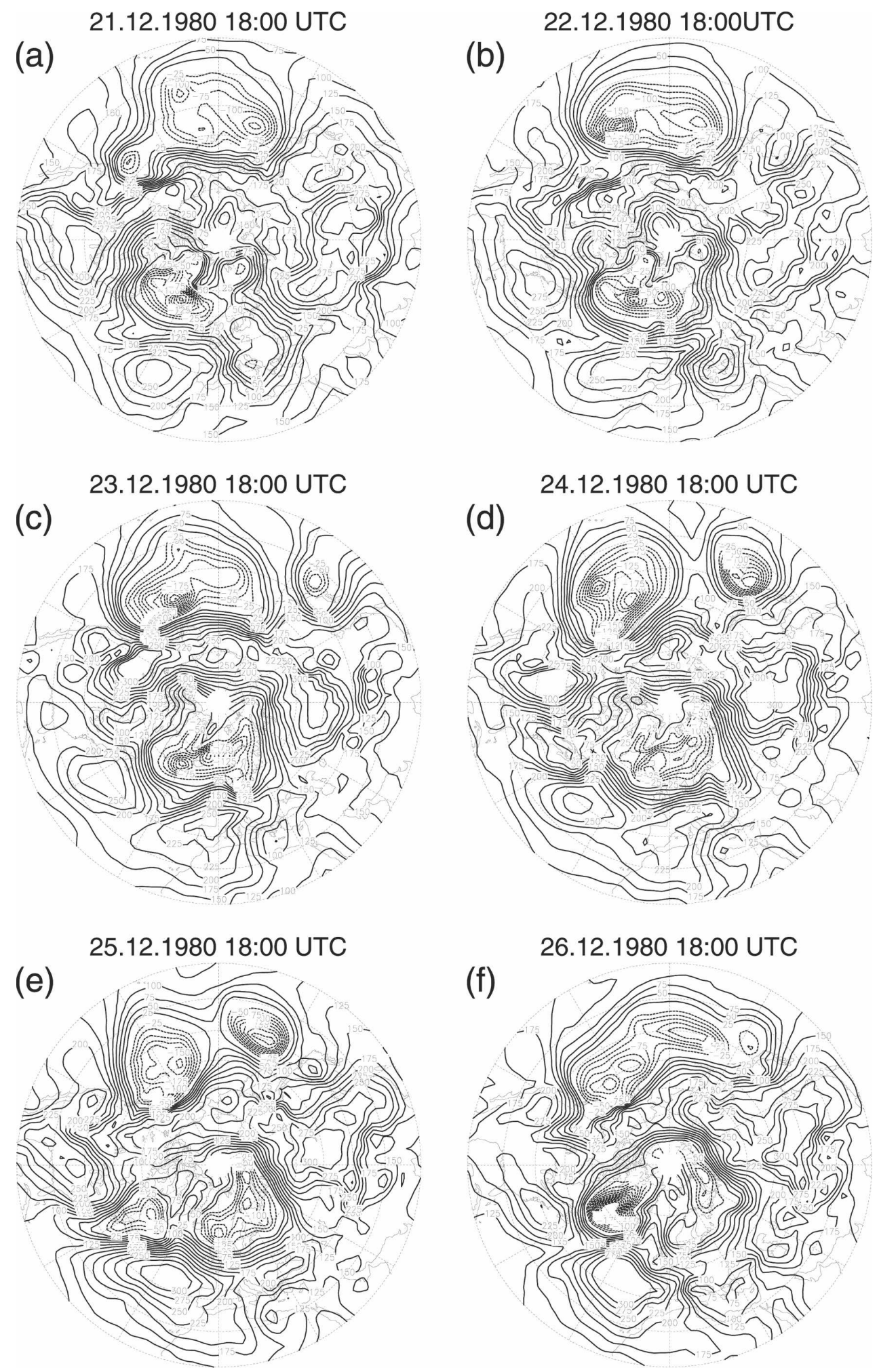

FIG. 6. 1000-hPa geopotential height fields for the period 1800 UTC 21-26 Dec 1980 (every $24 \mathrm{~h}$ ). 
TABLE 3. Winter and summer pairs of cyclones north to $20^{\circ} \mathrm{N}$ in ERA-40 and the ratio for cyclones with a minimum lifetime of 72 $\mathrm{h}$ using all three tracking schemes for the period 1961-90. Note that the ratio is always denoted by $\mathrm{N}$-pairs/maximum possible number of pair, which is the lower number of cyclones found in schemes.

\begin{tabular}{llll}
\hline \hline Season & Comparison & Pairs & Ratio \\
\hline DJF & HAM AUS & 2216 & $77 \%$ \\
& HAM ETH & 1567 & $70 \%$ \\
\multirow{2}{*}{ JJA } & AUS ETH & 1500 & $67 \%$ \\
& HAM AUS & 2452 & $80 \%$ \\
& HAM ETH & 1716 & $78 \%$ \\
& AUS ETH & 1630 & $74 \%$ \\
\hline
\end{tabular}

ficients, varying from 0.62 to 0.76 in winter and 0.69 to 0.77 in summer. These correlation coefficients are in the range of the ones estimated between the two reanalysis datasets, using the HAM scheme. Trends in the number of cyclones in the period 1961-90 are, however, rather different between the schemes. They agree for the ETH and the HAM scheme showing a significant negative trend from 1961 to 1990 in the Atlantic in winter. Another agreement between all schemes is that trends of opposite signs are observed between the high and midlatitudes of the North Atlantic, similar to findings in section 3 and Wang et al. (2006). However, in summer and in winter even the signs of the trends disagree for the Pacific. This is important as it shows that estimates of trends are dependent on the cyclone tracking and detection scheme. Moreover, differences in trends of the number of cyclones are able to contami-
TABLE 4. Winter and summer numbers of cyclones north to $20^{\circ} \mathrm{N}$ in ERA-40 with a minimum lifetime of $72 \mathrm{~h}$ for all schemes for the period 1961-90.

\begin{tabular}{cccc}
\hline \hline Method & HAM & AUS & ETH \\
\hline Number (DJF) & 3035 & 2883 & 2226 \\
Number (JJA) & 3554 & 3064 & 2195 \\
\hline
\end{tabular}

nate the cyclone activity used in other studies, such as Raible and Blender (2004) or Wang et al. (2006). Note that the cyclone intensity is not investigated as this is not available for all schemes and the definitions deviate from scheme to scheme.

To gain more insight into the similarities and discrepancies between the different methods, the cyclone center density is analyzed. Comparing the HAM with the AUS tracking scheme in winter, the cyclone center density exhibits weak but highly structured differences (Fig. 8a). The HAM method slightly underestimates the main cyclone track areas as well as the major cyclone genesis regions in eastern Canada and at the coast of Japan in the Pacific basin (not significant at the 5\% level). In the lysis areas near the Aleutian in the Pacific and between Greenland and Scandinavia, the HAM method identifies more cyclones than the AUS tracking scheme. The HAM method detects significantly more cyclones than AUS method in the secondary storm activity areas (e.g., the Mediterranean and Siberia/Kamchatka). A comparison of the results with manually detected cyclones (Brümmer et al. 2000; Schinke 1993) shows that the HAM method is more realistic than the (a)

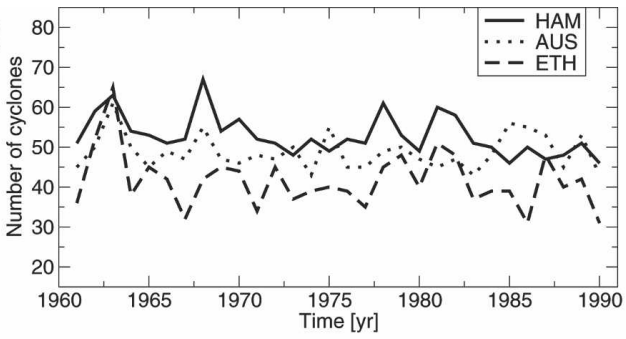

(c)

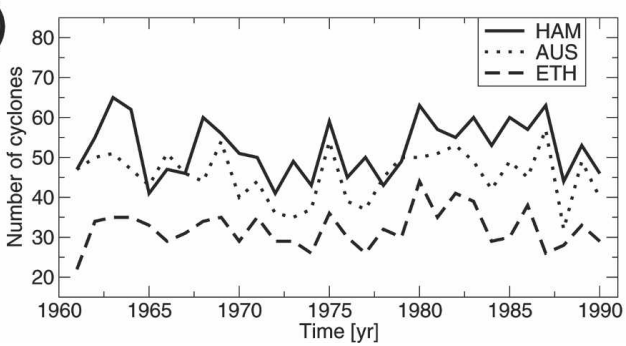

(b)

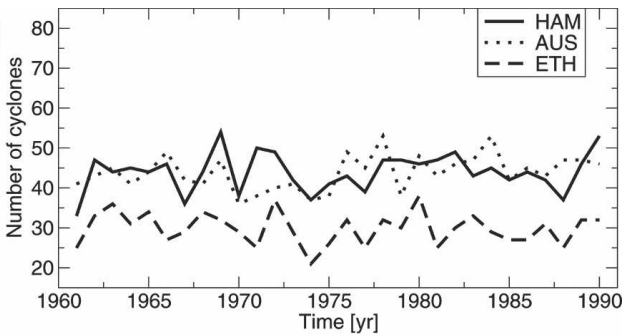

(d)

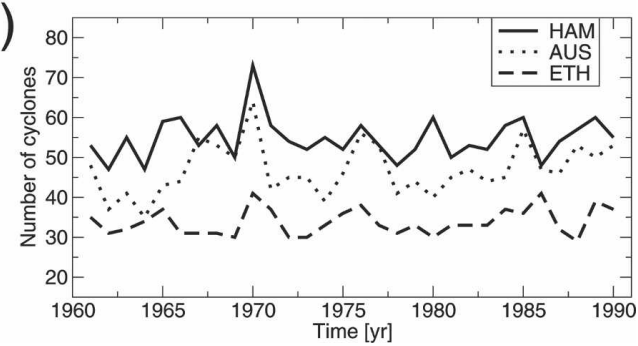

FIG. 7. Number of cyclones with a lifetime of at least $72 \mathrm{~h}$ in (a), (b) DJF and (c), (d) JJA for the (a), (c) Atlantic $\left(30^{\circ}-75^{\circ} \mathrm{N}, 100^{\circ} \mathrm{W}-60^{\circ} \mathrm{E}\right)$ and the (b), (d) Pacific $\left(30^{\circ}-75^{\circ} \mathrm{N}, 90^{\circ} \mathrm{E}-110^{\circ} \mathrm{W}\right)$ using all methods and the ERA-40 data. 
(a) HAM-AUS

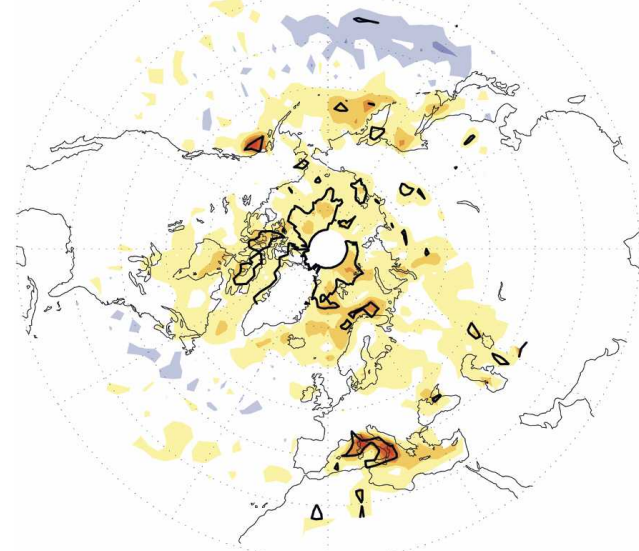

(c) HAM-ETH

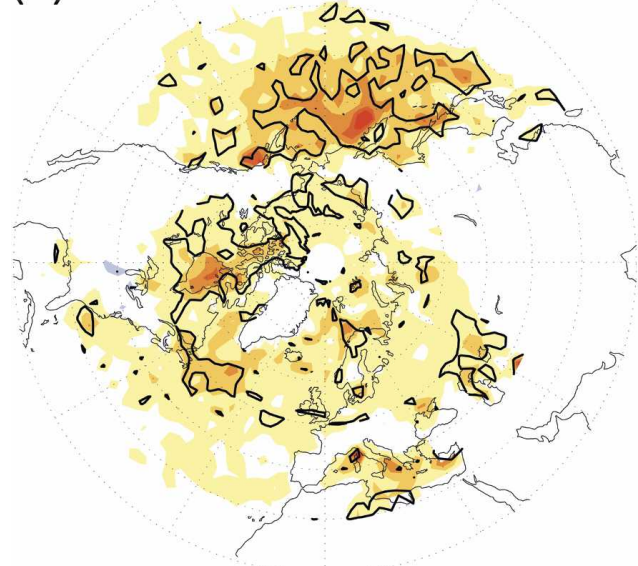

(e) AUS-ETH

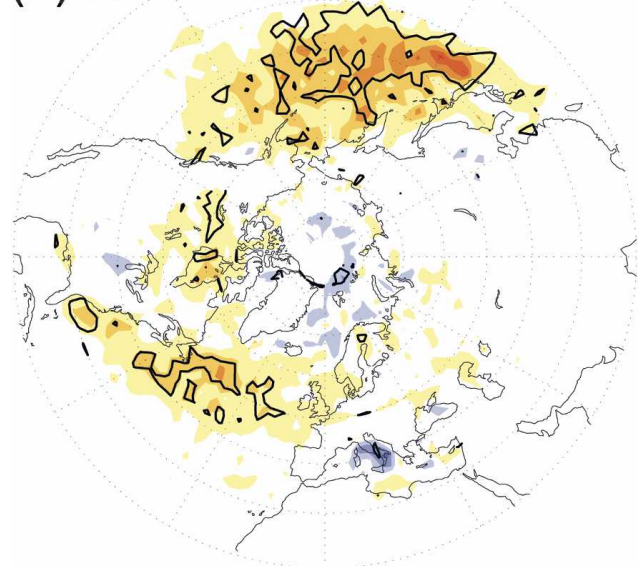

$\begin{array}{llllllllll}-9 & -7 & -5 & -3 & -1 & 1 & 3 & 5 & 7 & 9\end{array}$ (b)

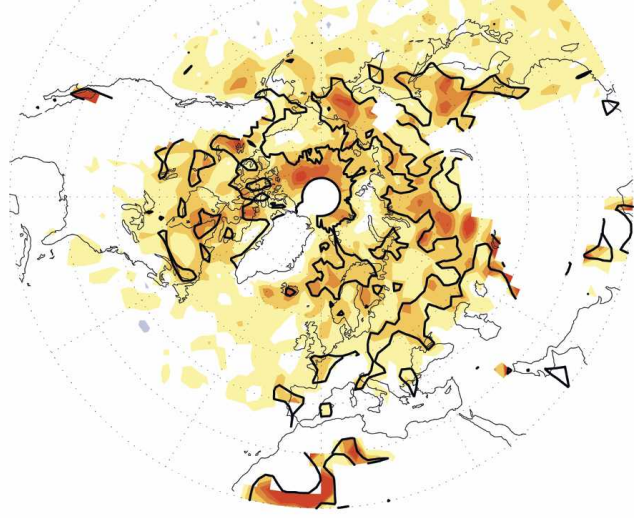

(d)

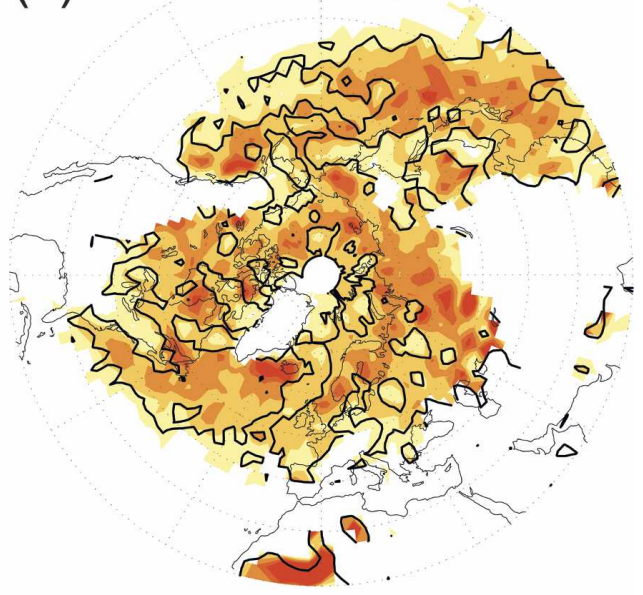

(f)

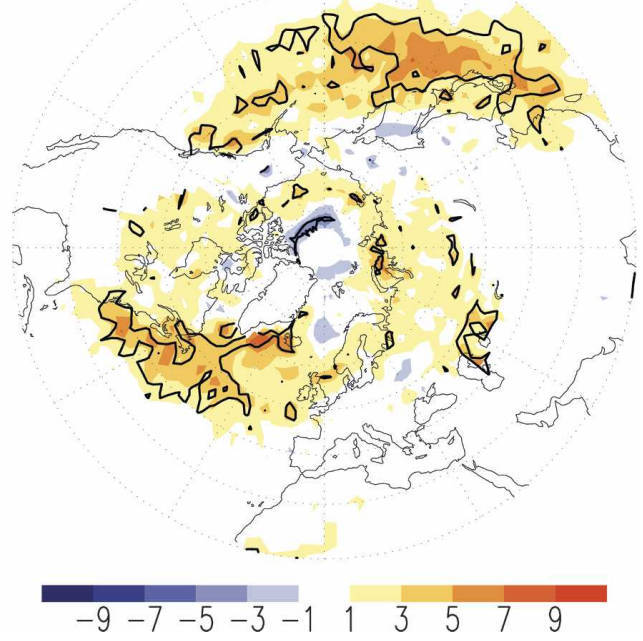

FIG. 8. Difference between all tracking schemes (HAM, AUS, and ETH) in total cyclone center density \{which exceed a lifetime of at least $72 \mathrm{~h}\left[\right.$ No. $\left.\left.(1000 \mathrm{~km})^{-2}\right]\right\}$ for the period 1961-90: (a), (c), (e) DJF and (b), (d), (f) JJA. Thick contours indicate the $5 \%$ significance level. 
AUS approach in these areas. In summer the HAM method identifies more cyclones over the genesis region in the Pacific (nearby Japan) and over the Gulf of California (Fig. 8b). Again, the HAM method finds more cyclones in the secondary storm activity areas than the AUS approach. To explain these deviations in the secondary storm activity areas, note that the standard parameters used for the AUS scheme are set to optimally identify large-scale midlatitude cyclones. For instance, if either the concavity criteria $[2.22 \mathrm{gpm}$ $\left({ }^{\circ} \text { latitude }\right)^{-2}$ ] or the radius at which this criteria was evaluated ( $3^{\circ}$ latitude) was reduced, the AUS scheme would identify more small-scale cyclones typically found in the secondary storm tracks. The HAM method also identifies more cyclones over central Siberia than AUS, which is a hint that the HAM method tends to include weak heat lows over continental areas. Tests show that this could be avoided, if the threshold of the geopotential height gradient, which a cyclone should exceed once in its lifetime, is increased in the HAM method. But note that this setting will also decrease weak cyclones elsewhere, for example, in areas of interest like the Mediterranean. In summary, the comparison of the two schemes shows small differences with some pronounced regional patterns, but applying specific parameter settings of the methods could overcome some deviations, for example, the underestimation of the secondary storm activity areas of the AUS scheme, as suggested by Pinto et al. (2005). They found that avoiding the smoothing of the Laplacian field in the AUS scheme leads to a more realistic representation of smaller-scale cyclones in the secondary storm track areas. More details of the specific parameter setting are found in their publication.

Comparing the HAM with the ETH method shows that HAM identifies overall more cyclones in winter and summer, but not uniformly (Figs. 8c,d). In winter, both methods nearly agree over the eastern part of the North Atlantic and central to northern Europe, but they deviate strongly over the Mediterranean, the western part of the North Atlantic, and the entire Pacific, where HAM identifies more cyclones than ETH (Fig. 8c). In summer this difference increases, showing again that HAM includes many heat lows over, for example, Siberia (Fig. 8d). The deviations in the genesis regions in both seasons are again a hint that the closed contour condition of the ETH scheme is rather strict to identify cyclones in the early open wave phase of their life cycle.

Comparing the AUS with the ETH scheme we find that in both seasons the difference patterns are similar to the HAM versus ETH comparison, exhibiting an increased midlatitude cyclone track center density for the AUS method (Figs. 8e,f). But there are also some remarkable discrepancies. In winter the lysis region north of Iceland of the North Atlantic storm tracks is slightly less pronounced (insignificant) using the AUS method (Fig. 8e). The Mediterranean cyclone center density is significantly underestimated by the AUS compared to the ETH scheme. In summer the AUS scheme finds significantly more cyclones than the ETH scheme near the genesis regions in the Pacific and the Atlantic (Fig. 8f). This is again a hint that the ETH scheme tends to underestimate cyclones in their early state of the life cycle.

In the light of the changes due to different reanalysis datasets (section 3 and Fig. 2), the cyclone center density shows stronger deviations between the schemes. This is particularly evident in the genesis regions of the storm tracks and in the secondary storm track areas. The deviations are stronger in summer than in winter, which is similar to the results for different reanalysis datasets, suggesting that some schemes, in particular the HAM scheme, react differently to the generally weaker lows in summer and therefore might need a tuning of the sensitive parameters, for example, to exclude heat lows more rigorously.

\section{Concluding remarks}

The aim of the study was twofold: to compare cyclone characteristics in the two reanalysis datasets of ERA-40 and NCEP-NCAR and to present similarities and discrepancies, when applying different commonly used cyclone detection and tracking schemes to ERA40. The focus is on strong and long-living cyclones, which is particularly relevant for likely third party users of this study, like the insurance industry.

The comparison of the two reanalyses yields both differences in the number of cyclones and the cyclone intensity. Systematically more cyclones are found in ERA-40. They are also deeper, mainly because of the fact that ERA-40 is obtained from a higher-resolution model than the NCEP-NCAR reanalysis (Hodges et al. 2003; Wang et al. 2006; Trigo 2006). The interannual variability of the number of cyclones and the extreme cyclone intensity is significantly correlated between the datasets; however, the correlations are higher for the extreme cyclone intensity, suggesting that the number of cyclones might not be as robust as the extreme cyclone intensity to describe the interannual variability of a season. Concerning trends, it is notable that all available cyclone characteristics, like cyclone number, extreme intensity, and activity, should be analyzed separately to gain more insight. Cyclone activity might lead to misinterpretations, as significant but counterintuitive trends of cyclone number and extreme intensity could 
cancel each other in the cyclone activity measure. This is important for the insurance industry because high losses occur mainly during extremely intense storms. As loss and intensity are related in a nonlinear way, the insurance industry is interested in both the intensity and frequency of such events. Moreover, there are deviations between ERA-40 and the NCEP-NCAR reanalysis; for example, the NCEP-NCAR reanalysis data tend to show more significant trends than ERA40. In some seasons trends of opposite signs are found, when comparing ERA-40 with the NCEP-NCAR reanalysis. The cyclone climatology, illustrated by the cyclone center density, shows rather weak systematic changes between the reanalysis datasets resembling earlier findings by Hodges et al. (2003), for example, the land-sea mask impact over the Hudson Bay and the dynamic impact of the orography in the lee of Greenland. However, the seasonality is almost identical in both datasets. The individual track comparison analysis shows a rather good agreement between the two datasets with no systematic differences between the seasons. Note that the results of this comparison also apply to the entire joint period of the reanalysis datasets from 1957-2002; however, for brevity these results were not included.

Similar climatologies of midlatitude cyclones are produced by three different cyclone detecting and tracking schemes. The interannual variability of the number of cyclones is well represented in all tracking methods with correlation coefficients of up to 0.76 , which is of the same order as the correlations between the two reanalysis datasets. However, trends in the number of cyclones deviate from scheme to scheme, suggesting that trend estimates have to be treated with caution. Systematic discrepancies in the cyclone center density between the schemes can be explained by parameter settings, as illustrated by a case study. Other problems of the schemes are the inclusion of artificial cyclone tracks or very weak heat lows and the difficulties of determining the correct track from the fields of cyclone centers. Moreover, some cyclone tracks are not detected by one or more schemes. Although specifics of methodology choices have some impact on the results, structural differences are rather small. Thus, all methods are suitable for model applications, for example, in $\mathrm{CO}_{2}$ scenario simulations (Schubert et al. 1998; Leckebusch and Ulbrich 2004) or sensitivity studies concerning the ocean's impact on cyclones (Zolina and Gulev 2003; Raible and Blender 2004) as well as studies investigating the cyclones' relation to long-term decadal variability (Raible et al. 2004; Luksch et al. 2005). The current study provides a systematic comparison between three state-of-the-art cyclone detection and tracking methods, illustrating the basic characteristics of each scheme as well as their strengths and weaknesses. These deviations are discussed in the context of uncertainty spanned by two different reanalysis datasets using one method. A potential user of such cyclone detection and tracking methods should always proceed with caution, as the interpretation of cyclone tracks may depend on the scheme or the specific parameter setting chosen by the user. This is in particular essential in the trend analysis, as suggested by this study. Therefore, in future trend investigations, we suggest either to use more than one detection and tracking method or to conduct Monte Carlo methods on the most sensitive parameters of such detection and tracking methods. Moreover, more than one dataset or multimodel output should also be considered to obtain robust results in trends.

Acknowledgments. This work is supported by the National Centre for Competence in Research (NCCR) on Climate funded by the Swiss National Science Foundation. ERA-40 data used in this study have been provided by European Centre for Medium-Range Weather Forecasts (ECMWF; more information is available online at http://data.ecmwf.int/data/index.html) and were obtained from Meteo Swiss. Storage capacity is provided by the Swiss National Supercomputing Centre (CSCS). The NCEP-NCAR reanalysis data have been obtained from the National Oceanic and Atmospheric Administration (NOAA; more information is available online at http://www.cdc.noaa.gov/cdc/data.ncep. reanalysis.html). Thanks are due to the three anonymous referees for their constructive comments that helped to improve the manuscript substantially.

\section{APPENDIX}

\section{Distance of Two Cyclone Trajectories}

The spatiotemporal distance is introduced as a measure for the deviation of cyclone trajectories in two independent datasets (Blender and Schubert 2000). This measure is applicable in situations with different grids and different observation times. A trajectory is given by the positions and times $\left\{x_{1}\left(a_{1}\right), y_{1}\left(a_{1}\right), t_{1}\left(a_{1}\right)\right\}$ with the age of cyclone $a_{1}=0, \ldots, A_{1}$, and the total lifetime $A_{1}$. The second trajectory is $\left\{x_{2}\left(a_{2}\right), y_{2}\left(a_{2}\right)\right.$, $\left.t_{2}\left(a_{2}\right)\right\}$, and $a_{2}=0, \ldots, A_{2}$ with the lifetime $A_{2}$. Below continuous values for the trajectories are used for the calculation; the extension of the analysis to discrete time steps is straightforward. The spatiotemporal distance $D_{12}$ between two trajectories is defined as

$$
D_{12}^{2}=\frac{1}{A_{1} A_{2}}\left[\sigma_{12}^{2}-\frac{1}{2}\left(\sigma_{1}^{2}+\sigma_{2}^{2}\right)\right],
$$


with the variance spanned by the two trajectories given by

$$
\begin{aligned}
\sigma_{12}^{2}= & \frac{1}{A_{1} A_{2}} \int_{0}^{A_{1}} d a_{1} \int_{0}^{A_{2}} d a_{2}\left\langle\alpha \left\{\left[x_{1}\left(a_{1}\right)-x_{2}\left(a_{2}\right)\right]^{2}\right.\right. \\
& \left.\left.+\left[y_{1}\left(a_{1}\right)-y_{2}\left(a_{2}\right)\right]^{2}\right\}+\beta\left[t_{1}\left(a_{1}\right)-t_{2}\left(a_{2}\right)\right]^{2}\right\rangle .
\end{aligned}
$$

In Eq. (A1) the variances $\sigma_{1}^{2}$ and $\sigma_{2}^{2}$ of the individual trajectories are subtracted. The factors $\alpha$ and $\beta$ determine the weights of spatial and temporal distances. Based on a synoptic speed $U=10 \mathrm{~m} \mathrm{~s}^{-1}, \beta$ is determined by $\beta=U^{2} \alpha$, with $\alpha=1$. Further details are found in Blender and Schubert (2000).

\section{REFERENCES}

Björck, S., and L. B. Clemmensen, 2004: Aeolian sediment in raised bog deposits, Halland, SW Sweden: A new proxy record of Holocene winter storminess variation in southern Scandinavia? Holocene, 14, 677-688.

Blackmon, M. L., 1976: A climatological spectral study of the 500 $\mathrm{mb}$ geopotential height of the Northern Hemisphere. J. Atmos. Sci., 33, 1607-1623.

Blender, R., and M. Schubert, 2000: Cyclone tracking in different spatial and temporal resolutions. Mon. Wea. Rev., 128, $377-$ 384.

— K. Fraedrich, and F. Lunkeit, 1997: Identification of cyclone-track regimes in the North Atlantic. Quart. J. Roy. Meteor. Soc., 123, 727-741.

Brümmer, B., S. Thiemann, and A. Kirchgässner, 2000: A cyclone statistics for the Arctic based on European Centre re-analysis data. Meteor. Atmos. Phys., 75, 233-250.

De Jong, R., S. Björck, L. Björkman, and L. B. Clemmensen, 2006: Storminess variations during the last 6500 years as reconstructed from an ombrotrophic bog in Halland, southwest Sweden. J. Quat. Sci., 21, 905-919.

Goyette, S., M. Beniston, D. Caya, R. Laprise, and P. Jungo, 2001: Numerical investigation of an extreme storm with the Canadian Regional Climate Model: The case study of windstorm VIVIAN, Switzerland, February 27, 1990. Climate Dyn., 18, 145-168.

Gulev, S. K., O. Zolina, and S. Grigoriev, 2001: Extratropical cyclone variability in the Northern Hemisphere winter from NCEP/NCAR reanalysis data. Climate Dyn., 17, 795-809.

Hanson, C. E., J. P. Palutikof, and T. D. Davies, 2004: Objective cyclone climatologies of the North Atlantic-A comparison between ECMWF and NCEP reanalyses. Climate Dyn., 22, 757-769.

Hodges, K. I., 1994: A general method for tracking analysis and its application to meteorological data. Mon. Wea. Rev., 122, 2573-2586.

— B. J. Hoskins, J. Boyle, and C. Thorncroft, 2003: A comparison of recent reanalysis datasets using objective feature tracking: Storm tracks and tropical easterly waves. Mon. Wea. Rev., 131, 2012-2037.

Kalnay, E., and Coauthors, 1996: The NCEP/NCAR 40-Year Reanalysis Project. Bull. Amer. Meteor. Soc., 77, 437-471.

Kharin, V. V., and F. Zwiers, 2000: Changes in the extremes in an ensemble of transient climate simulations with a coupled atmosphere-ocean GCM. J. Climate, 13, 3760-3788.
- and - 2005: Estimating extremes in transient climate change simulations. J. Climate, 18, 1156-1173.

Kistler, R., and Coauthors, 2001: The NCEP-NCAR 50-Year Reanalysis: Monthly means CD-ROM and documentation. Bull. Amer. Meteor. Soc., 82, 247-267.

König, W., R. Sausen, and F. Sielmann, 1993: Objective identification of cyclones in GCM simulations. J. Climate, 6, 22172231.

Köppen, W., 1881: Die Zugbahnen der barometrischen Minima in Europa und auf dem nordatlantischen Ocean und ihr Einfluss auf Wind und Wetter bei uns. Mitt. Geogr. Ges. Hamb., 1, 76-97.

Lau, N.-C., 1988: Variability of the observed midlatitude storm tracks in relation to low-frequency changes in the circulation pattern. J. Atmos. Sci., 45, 2718-2743.

Leckebusch, G. C., and U. Ulbrich, 2004: On the relationship between cyclones and extreme windstorm events over Europe under climate change. Global Planet. Change, 44, 181-193.

Luksch, U., C. C. Raible, R. Blender, and K. Fraedrich, 2005: Cyclone track and decadal northern hemispheric regimes. Meteor. Z., 14, 747-753.

Mailier, P. J., D. B. Stephenson, C. A. T. Ferro, and K. I. Hodges, 2006: Serial clustering of extratropical cyclones. Mon. Wea. Rev., 134, 2224-2240.

Murray, R. J., and I. Simmonds, 1991a: A numerical scheme for tracking cyclone centres from digital data, Part I: Development and operation of the scheme. Aust. Meteor. Mag., 39, $155-166$.

— centres from digital data. Part II: Application to January and July general circulation model simulations. Aust. Meteor. Mag., 39, 167-180.

Pinto, J., T. Spangehl, U. Ulbrich, and P. Speth, 2005: Sensitivities of a cyclone detection and tracking algorithm: Individual tracks and climatology. Meteor. Z., 14, 823-838.

Raible, C. C., 2007: On the relation between extremes of midlatitude cyclones and the atmospheric circulation using ERA40. Geophys. Res. Lett., 34, L07703, doi:10.1029/2006GL029084.

_ cyclonic variability in GCM simulations with different ocean representations. Climate Dyn., 22, 239-248.

—, U. Luksch, and K. Fraedrich, 2004: Precipitation and Northern Hemisphere regimes. Atmos. Sci. Lett., 5, 43-55.

—, M. Yoshimori, T. F. Stocker, and C. Casty, 2007: Extreme midlatitude cyclones and their implications to precipitation and wind speed extremes in simulations of the Maunder Minimum versus present day conditions. Climate Dyn., 28, 409-423.

Schinke, H., 1993: On the occurrence of deep cyclones over Europe and the North Atlantic in the period 1930-1991. Contrib. Atmos. Phys., 66, 223-237.

Schubert, M., J. Perlwitz, R. Blender, K. Fraedrich, and F. Lunkeit, 1998: North Atlantic cyclones in $\mathrm{CO}_{2}$-induced warm climate simulations: Frequency, intensity, and tracks. Climate Dyn., 14, 827-838.

Sickmöller, M., R. Blender, and K. Fraedrich, 2000: Observed winter cyclone tracks in the Northern Hemisphere in reanalysed ECMWF data. Quart. J. Roy. Meteor. Soc., 126, 591-620.

Simmonds, I., and K. Keay, 2000: Mean Southern Hemisphere extratropical cyclone behavior in the 40-year NCEP-NCAR reanalysis. J. Climate, 13, 873-885. 
, and - 2002: Surface fluxes of momentum and mechanical energy over the North Pacific and North Atlantic Oceans. Meteor. Atmos. Phys., 80,1-18.

, - - and E.-P. Lim, 2003: Synoptic activity in the seas around Antarctica. Mon. Wea. Rev., 131, 272-288.

— , R. Murray, and R. Leighton, 1999: A refinement of cyclone tracking methods with data from FROST. Aust. Meteor. Mag., Special Issue, 35-49.

Sinclair, M. R., 1994: An objective cyclone climatology for the Southern Hemisphere. Mon. Wea. Rev., 122, 2239-2256.

- 1995: A climatology of cyclogenesis for the Southern Hemisphere. Mon. Wea. Rev., 123, 1601-1619.

_ 1997: Objective identification of cyclones and their circulation intensity, and climatology. Wea. Forecasting, 12, 595-612.

Trigo, I., 2006: Climatology and interannual variability of stormtracks in the Euro-Atlantic sector: A comparison between ERA-40 and NCEP/NCAR reanalyses. Climate Dyn., 26, 127-143.

Ueno, K., 1993: Interannual variability of surface cyclone tracks, atmospheric circulation patterns, and precipitation patterns in winter. J. Meteor. Soc. Japan, 71, 655-671.

Uppala, S. M., and Coauthors, 2005: The ERA-40 re-analysis. Quart. J. Roy. Meteor. Soc., 131, 2961-3012.
Van Bebber, W. J., 1891: Die Zugstrassen der barometrischen Minima nach Bahnenkarten der Deutschen Seewarte für den Zeitraum von 1870-1890. Meteor. Z., 8, 361-366.

Wallace, J. M., G.-H. Lim, and M. L. Blackmon, 1988: Relationship between cyclone tracks, anticyclone tracks, and baroclinic waveguides. J. Atmos. Sci., 45, 439-462.

Wang, X. L., V. R. Swail, and F. W. Zwiers, 2006: Climatology and changes of extratropical cyclone activity: Comparison of ERA-40 with NCEP-NCAR reanalysis for 1958-2001. J. Climate, 19, 3145-3166.

Wernli, H., and C. Schwierz, 2006: Surface cyclones in the ERA40 data set (1958-2001). Part I: Novel identification method and global climatology. J. Atmos. Sci., 63, 2486-2507.

Wild, M., P. Calanca, S. C. Scherrer, and A. Ohmura, 2003: Effects of polar ice sheets on global sea level in high-resolution greenhouse scenarios. J. Geophys. Res., 108, 4165, doi:10.1029/2002JD002451.

Zolina, O., and S. K. Gulev, 2002: Improving the accuracy of mapping cyclone numbers and frequencies. Mon. Wea. Rev., 130, 748-759.

_, and 2003: Synoptic variability of ocean-atmosphere turbulent fluxes associated with atmospheric cyclones. J. Climate, 16, 2717-2734. 